\title{
Systems Neuroscience of Psychosis: Mapping Schizophrenia Symptoms onto Brain Systems
}

\author{
Werner Strik Katharina Stegmayer Sebastian Walther Thomas Dierks \\ University Hospital of Psychiatry, University of Bern, Bern, Switzerland
}

\section{Keywords}

Systems Neuroscience of Psychosis · Schizophrenia .

Mapping $\cdot$ Brain systems

\begin{abstract}
Schizophrenia research has been in a deadlock for many decades. Despite important advances in clinical treatment, there are still major concerns regarding long-term psychosocial reintegration and disease management, biological heterogeneity, unsatisfactory predictors of individual course and treatment strategies, and a confusing variety of controversial theories about its etiology and pathophysiological mechanisms. In the present perspective on schizophrenia research, we first discuss a methodological pitfall in contemporary schizophrenia research inherent in the attempt to link mental phenomena with the brain: we claim that the timehonored phenomenological method of defining mental symptoms should not be contaminated with the naturalistic approach of modern neuroscience. We then describe our Systems Neuroscience of Psychosis (SyNoPsis) project, which aims to overcome this intrinsic problem of psychiatric research. Considering schizophrenia primarily as a disorder of interindividual communication, we developed a neurobiologically informed semiotics of psychotic disorders, as well as an operational clinical rating scale. The novel psychopa-
\end{abstract}

\section{KARGER}

(C) 2017 S. Karger AG, Basel

E-Mail karger@karger.com

www.karger.com/nps thology allows disentangling the clinical manifestations of schizophrenia into behavioral domains matching the functions of three well-described higher-order corticobasal brain systems involved in interindividual human communication, namely, the limbic, associative, and motor loops, including their corticocortical sensorimotor connections. The results of several empirical studies support the hypothesis that the proposed three-dimensional symptom structure, segregated into the affective, the language, and the motor domain, can be specifically mapped onto structural and functional abnormalities of the respective brain systems. New pathophysiological hypotheses derived from this brain system-oriented approach have helped to develop and improve novel treatment strategies with noninvasive brain stimulation and practicable clinical parameters. In clinical practice, the novel psychopathology allows confining the communication deficits of the individual patient, shifting attention from the symptoms to the intact resources. We have studied this approach and observed important advantages for therapeutic alliances, personalized treatment, and de-escalation strategies. Future studies will further conjoin clinical definitions of psychotic symptoms with brain structures and functions, and disentangle structural and functional deficit patterns within these systems to identify neurobiologically distinct subsyndromes. Neurobiologically homogeneous patient groups may provide new momentum for treatment re-
Prof. Werner Strik

University Hospital of Psychiatry, University of Bern Bolligenstrasse 111

$\mathrm{CH}-3060$ Bern (Switzerland)

E-Mail werner.strik@upd.unibe.ch 
search. Finally, lessons learned from schizophrenia research may contribute to developing a comprehensive perspective on human experience and behavior that integrates methodologically distinct, but internally consistent, insights from humanities and neuroscience.

(c) 2017 S. Karger AG, Basel

\section{Introduction}

Medical diagnoses should be reliable and combine valid information about the conditions and causes, pathophysiological cascades, treatment, and prognosis of diseases. Further, they should index homogeneous patient groups for epidemiological, sociological, and biological research. Since the 1980s, psychiatric classification has considerably improved in reliability. However, its validity in terms of causes, treatment, prognosis, and health care costs is still far from being satisfactory [1].

In the case of major psychiatric disorders such as schizophrenia and affective disorders, the diagnoses are still firmly anchored in the century-old taxonomy and clinical descriptions of the German psychiatrist Emil Kraepelin. Recently, growing skepticism has developed towards these categories as to their potential for advancing the field. Recognizing the limitations of the present diagnostic manuals of mental disorders for research, in early 2009 the US National Institute of Mental Health (NIMH) introduced the Research Domain Criteria ( $\mathrm{RDoC})$ project [2]. $\mathrm{RDoC}$ aims to identify links between brain and behavior based on behavioral domains - for instance, valence and social processes - and their subdivision into functional constructs consisting of neurophysiological and neuropsychological dimensions (e.g., attention or working memory). These dimensions are expected to permit mechanistic hypotheses and empirical studies linking them with brain structures and functions from the molecular level to brain circuitries. The $\mathrm{RDoC}$ concept assumes that mental illness is based on dysfunctional brain circuits, that the tools of clinical neuroscience can identify these dysfunctions, and that genetic and clinical neuroscience data will yield biosignatures that can be translated into clinical interventions and management [3]. While $\mathrm{RDoC}$ domains are important to capture some of the psychosis dimensions, they fall short of assessing motor abnormalities, thought disorders, or reality distortion [4]. RDoC thus relies on intermediate constructs to link brain and behavior, rather than on clinical symptoms, syndromes, and disorders (Fig. 1).

SyNoPsis: Mapping Schizophrenia Symptoms onto Brain Systems

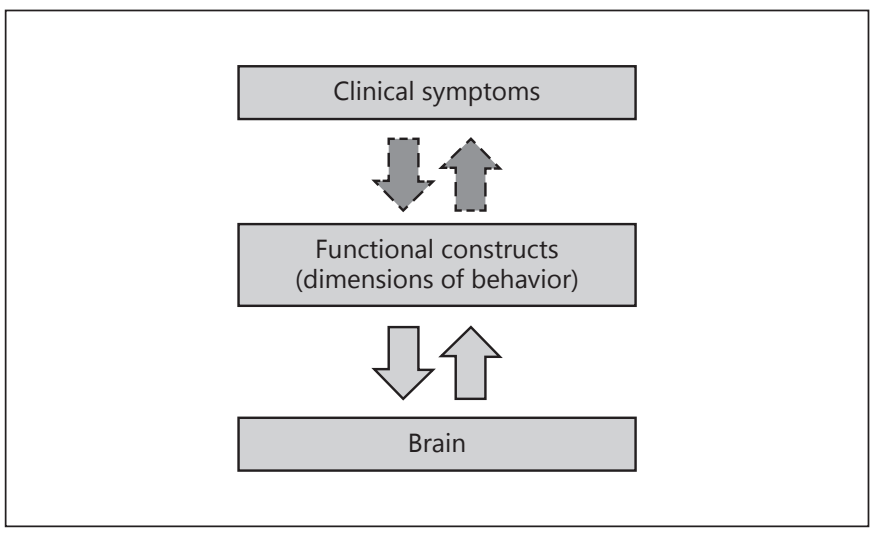

Fig. 1. The Research Domain Criteria (RDoC) project consistently applies empirical methods to study the link between functional constructs and brain circuits. However, the relationship of these constructs to clinical symptoms remains unclear.

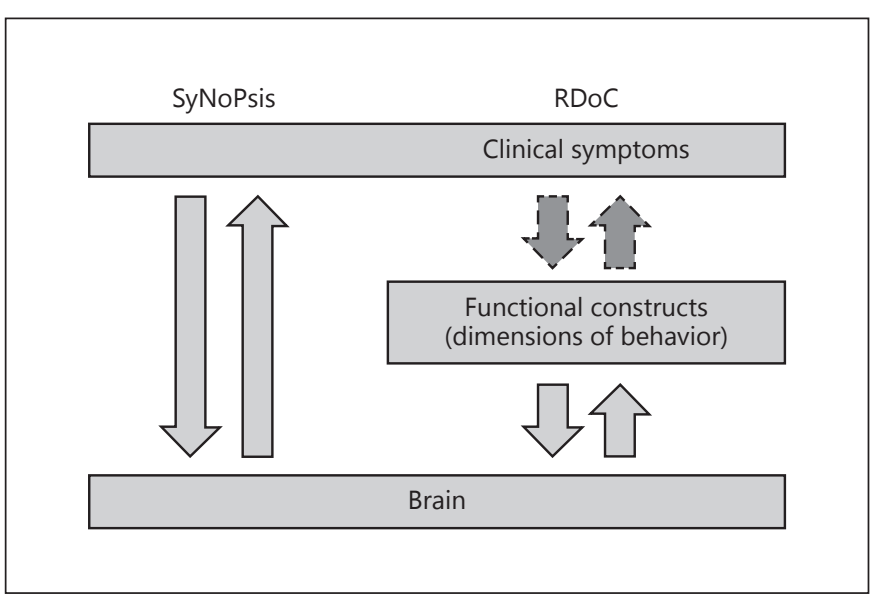

Fig. 2. The Systems Neuroscience of Psychosis (SyNoPsis) project links brain functions directly to clinical signs and symptoms, without referring to intermediate constructs. This approach requires a "neurobiologically informed" semiotics of psychotic behavior and experience.

In contrast, since the late 1990s, we have pursued the project Systems Neuroscience of Psychosis (SyNoPsis; www.synopsis.net), which aims at a direct link between a revised phenomenology of psychoses and brain circuits, without the use of intermediate neurophysiological or neuropsychological constructs (Fig. 2). The concept is based on a specific conceptual framework, various research methods, and numerous empirical studies. It started with the basic assumption that specific operational clinical signs and symptoms of psychosis are an

Neuropsychobiology 2017;75:100-116 101 
expression of dysfunctional higher-order brain systems which are specialized for human communication and intentional behavior. SyNoPsis identified behavioral dimensions representing pivotal aspects of psychotic signs and experience, which can be matched to known corticocortical and corticobasal brain circuits independently of traditional clinical subtypes or diagnostic borders.

To appreciate SyNoPsis, its method and vocabulary must be clarified. In the subsequent chapters, we introduce the theoretical framework, the brain circuits addressed by our translational research, the novel, neurobiologically informed semiotics of psychosis, and a review of several empirical studies supporting the concept.

\section{Phenomenological, Dualistic, and Naturalistic Approaches in Psychiatric Research}

To explain complex human behavior and subjective experience, contemporary psychiatric research refers to contradictory theoretical backgrounds. An awareness of the different basic assumptions is critical to stop ongoing controversies in the field which are unproductive. To disentangle the different approaches, we here distinguish "phenomenological," "dualistic," and "naturalistic" strategies to handle the brain-mind problem in the context of psychiatric disorders.

\section{The Phenomenological Approach}

The phenomenological approach is based on a humanistic method. It applies empathy, narrative description, induction of general principles, and logical reasoning. First adapted to psychiatry by the philosopher and psychiatrist Karl Jaspers, it has deeply influenced the classic psychopathology of Kurt Schneider and Eugen Bleuler. These authors shaped the vocabulary of the major psychiatric disorders still in use in the international classification systems.

Jaspers explicitly intended to overcome the perceived dead end of late-19th-century neuroanatomical research. $\mathrm{He}$ felt that it had reached its summit with the discoveries of researchers such as Nissl, Broca, and Wernicke, and judged their interpretations of psychic phenomena to be exaggerated ("brain mythology"). He proposed a radical paradigm shift from empirical research to the methods of humanities to investigate mental phenomena. These methods would be the proper means to discover universal principles of the mind, and to explain complex disorders of human behavior. He explicitly disregarded the nature of the brain, and justified this, interestingly enough, not by a dogmatic rule, but by the lack of sufficient knowledge about the biology of mental disorders [5].

\section{The Dualistic Approach}

The dualistic approach has its origins in the Cartesian model of a material body coexisting with a metaphysical soul. In its current application to psychiatric neurosciences, the brain is considered the natural basis of an immaterial mind. By unknown mechanisms, the mind achieves an abstract reality with loosely connected phenomena and independent rules of causality. Today, this basic idea is often formulated with the term "emerging properties" to indicate mental phenomena.

The dualistic perspective is currently the leading paradigm in psychiatric research. It is often attributed to Emil Kraepelin, who combined the coeval phenomenology with its empirical methods. In particular, he developed a taxonomy of the major psychiatric disorders by phenomenological methods: empathy, narrative descriptions, abstraction of general principles, and logical reasoning about their causal relationships.

In current neurobiological research, Kraepelin's disease entities are still treated as fixed points. In fact, ambiguous results are usually interpreted as "heterogeneity," "overlap," or "common causes" of the classic disorders, but not as a challenge to the disease entities themselves. Thus, current psychiatric research implicitly still accepts the humanities as the appropriate domain of psychopathology and the natural science of neurobiology, but at the same time is endlessly struggling to integrate them into a unique perspective on mental disorders.

Recent attempts at correlative combinations of these domains are functional brain imaging studies of abstract psychological states such as romantic love [6], religious faith [7], and shame or guilt [8]. Also, apparently genuine brain functions like working memory or theory of mind are often abstracted to universal psychological principles instead of just referring to performances in specific tests. We argue that this type of correlation is not appropriate for understanding how complex behavior is produced by the working brain.

\section{The Naturalistic Approach}

The naturalistic approach aims at applying the methods of the natural sciences to both brain research and the study of complex behavioral disorders. It abstains from operating with abstract constructs as metaphysical principles of the mind. 
Applied to psychiatry, the naturalistic approach relies on an empirically defined, functional neuroanatomy, a clinical semiology consisting of unique patterns of observable behavior, and mechanistic models to link the two. Recent research has demonstrated that this strategy can even include the content of self-reports about subjective experiences such as auditory verbal hallucinations (AVHs) [9]. In this perspective, the mind and related subjective abstract phenomena do not have their own reality but are collective terms for a defined combination of observable behavior. To match these patterns of behavior on their potential biological bases, however, the semiology must be informed by the functional neuroanatomy of the brain.

One of the most noticeable exponents of this strategy was Carl Wernicke, who in the early 20th century tried to link his neuroanatomical insights to behavior and shaped his psychological terminology accordingly [10]. Also, in the 1950s Skinner proposed a rigorously empirical method of psychology, called "behaviorism." He exclusively referred to measures of observable behavior, and declared subjective experiences ("the black box") as inaccessible to empirical research [11]. As mentioned above, Wernicke was criticized for his "brain mythology" in his attempt to explain subjective experience and complex behavior with brain functions; Skinner, in contrast, was blamed for "reductionism," since he deliberately eclipsed subjective phenomena.

The development of operational diagnostic criteria with the Research Diagnostic Criteria (RDC) and DSMIII in the 1970s, stimulated by the empirical philosopher Carl Gustav Hempel, was an important step towards a consistent naturalistic approach to psychiatry $[12,13]$. However, this diagnostic method still contained inconsistencies, since it relied on the classic definitions of symptoms and diagnostic categories that had been created with the phenomenological method. Recently, there has been a trend towards further increasing the consistency of the naturalistic approach in psychiatric classification. This may be seen in the original intent to base the taxonomy of the DSM-5 on genetic findings wherever possible, as well as in the research conducted in the RDoC project of the NIMH, which aims to combine brain research with empirically defined dimensions of behavior. The progress in linking behavior to brain circuits in animals by optogenetics may support this trend.

\section{Consequences for Psychiatry and Neuroscience}

We conclude that clinical neuroscience still faces the antique problem of whether abstract terms refer to a dis-

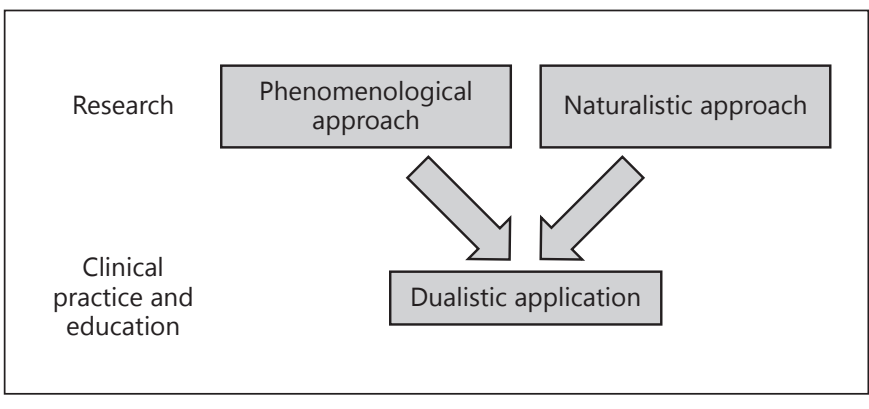

Fig. 3. Psychiatric research should be aware and explicit about its basic but conflicting assumptions - phenomenology and empiricism. Its research methods must be consistent, avoiding contaminations between phenomenological and naturalistic approaches. The necessary final compromise cannot be found in contaminated research methods, but in pragmatic conclusions for human coexistence.

tinct, metaphysical reality, or whether they are just deliberate definitions of real-world objects and events. Psychiatric research must be aware of the implicit assumptions about the nature of its objects, since the antithetic propositions of the naturalistic and the phenomenological approach result in incompatible methods. Conceptual contaminations lead to misconceptions and an inconsistent vocabulary. In other words, causal chains in naturalistic research must not contain metaphysical constructs.

Both approaches have substantially contributed to the field of psychiatry in the past century, and are certainly legitimate to increase our knowledge about deviant behavior and its treatment in medicine and society. Therefore, we claim that, in psychiatric research, the philosophical dispute about the truth or fallacy of the two competing basic propositions is gratuitous. Both blaming empirical neuroscience for its reductionism and blaming phenomenology for its difficulty in finding testable, mechanistic models linking psychological phenomena to the brain are a result of the undue contamination of metaphysical ideas with natural objects.

What does this mean for modern psychiatry? The dualistic approach is intriguing to integrate the two major methods of contemporary psychiatry, i.e., phenomenology and empirical neuroscience. This is, in fact, a useful compromise for the comprehensive application of our knowledge in patient care, education, ethics, politics, and law (Fig. 3). In research, however, the dualistic approach creates flaws in scientific hypotheses and experiments by mixing metaphysical entities and real-world objects with their contradictory basic assumptions and different rules 
of causality, a formal error introduced as a "category mistake" $[14]^{1}$.

Since phenomenology does not provide a method for studying the material brain, the only possible way to unravel this knot for translational psychiatric research is a consistent empirical approach to behavior. This strategy has been adopted by the RDoC project. It excludes the classic clinical symptoms and categories, and instead relies on intermediate, empirically defined neurobiological and neuropsychological constructs. This implies that these dimensions are the "missing link" between the brain and typical psychiatric symptoms. However, the causal gap between these constructs and clinical symptoms remains open, and their intermediate constructs are again at risk of "reification," i.e., abstraction beyond their empirical definitions.

SyNoPsis proposes a neurobiologically informed psychopathology, achieving its tenets by radically revising the vocabulary of psychiatric symptoms according to the best of our knowledge about higher brain functions, thereby developing a biologically informed semiotics of the psychiatric disorders addressed. This allows the establishment of mechanistic theories to directly link the functional anatomy of the brain to the typical abnormalities of behavior and experience occurring in the course of psychiatric disorders, without any need for intermediate functional constructs (Fig. 2).

\section{Outline of SyNoPsis}

SyNoPsis is a translational research project begun at the University Hospital of Bern at the turn of the millennium with the intent to match typical clinical symptoms of schizophrenia with dysfunctional brain systems. It works on the following basic assumptions: (1) the core feature of schizophrenia is a fundamental interpersonal communication breakdown; (2) its symptoms are an expression of dysfunctional sensorimotor and corticostriatal brain systems specialized for distinct communication domains ("candidate systems"); (3) formal features allow the mapping of typical symptoms onto these systems ${ }^{2}$ (Fig. 2); (4) the definitions of traditional psychopatholo$\mathrm{gy}^{3}$ must be revised according to our knowledge about the

1 Gilbert Ryle referred to this fallacy as searching for the "ghost in the machine" and proposed, as an example, the erroneous count of 3 objects on a meadow: 2 cows and a couple of cows. He claimed that the category mistake is not an error in detail, but in principle.

2 E.g., formal thought disorders and auditory verbal hallucinations on language, or catatonic behavior on motor functions.

3 E.g., "thought," "delusion," "volition," etc. functional neuroanatomy of the candidate systems; and (5) a neurobiologically informed psychopathology of psychoses will permit the generation of scientific hypotheses with falsifiable predictions about causal relationships between typical psychotic symptoms and dysfunctions of the candidate systems.

\section{Organization of Higher Brain Systems}

To avoid ambiguities, a clarification of the terminology is necessary. First, speaking about "hierarchical organization" of the brain, we here do not refer to a qualitative representation of psychic functions, but to the anatomical and functional architecture of the brain. This functional neuroanatomy displays features of a fractal organization: parallel elements account for different functional domains [15]. They are coupled through multiple organizational levels to systems with increasing complexity but with recurrent principles such as mutual inhibitory control, forming balanced loops. Hierarchical integration establishes anatomically and functionally segregated modules specialized for the highest brain functions $[16,17]$ involved in interpersonal communication.

Second, in the literature, the terms "brain circuitry," "neuronal network," and "brain system" are used to indicate a variety of different anatomical and functional instances, including anatomically defined local circuitries in primary cortical areas, but also diffuse modulatory neurotransmitter systems, the functional anatomy of perceptual modalities, and large-scale activation patterns observed during complex cognitive tasks without reference to any specific functional neuroanatomy. By the term "brain systems," we here explicitly refer to large-scale sensorimotor and corticobasal networks connecting highly specialized brain regions by means of long-range fiber tracts (Fig. 4).

\section{Brain Systems Involved in Communicative Human Behavior}

Based on the first assumption that psychosis reflects a fundamental communication breakdown, the brain functions involved in psychosis must be important for human communication. The brain systems processing the performance and perception of complex communicative behavior are anatomically and functionally segregated, large-scale sensorimotor and corticostriatal circuits. These prerequisites are met by three well-known corticostriatal loops: the associative, motor, and limbic loops. Figure 4 provides a schematic overview. Three corticocortical systems have distinct corticosubcortical loops, as indicated by the color coding. Within the basal ganglia, 
Fig. 4. Corticobasal loops and their respective overlap with corticocortical sensorimotor circuits. Blue: limbic loop; green: associative loop and its overlaps with the language system; red: motor loop and the corticocortical executive system. Colored arrows indicate distinct connections, black arrows indicate common connections. Note that the basal ganglia (bottom row) and thalamus (middle row) have distinct projection areas for the three systems. Thalamocortical connections are distinct, multiple, and reciprocal.

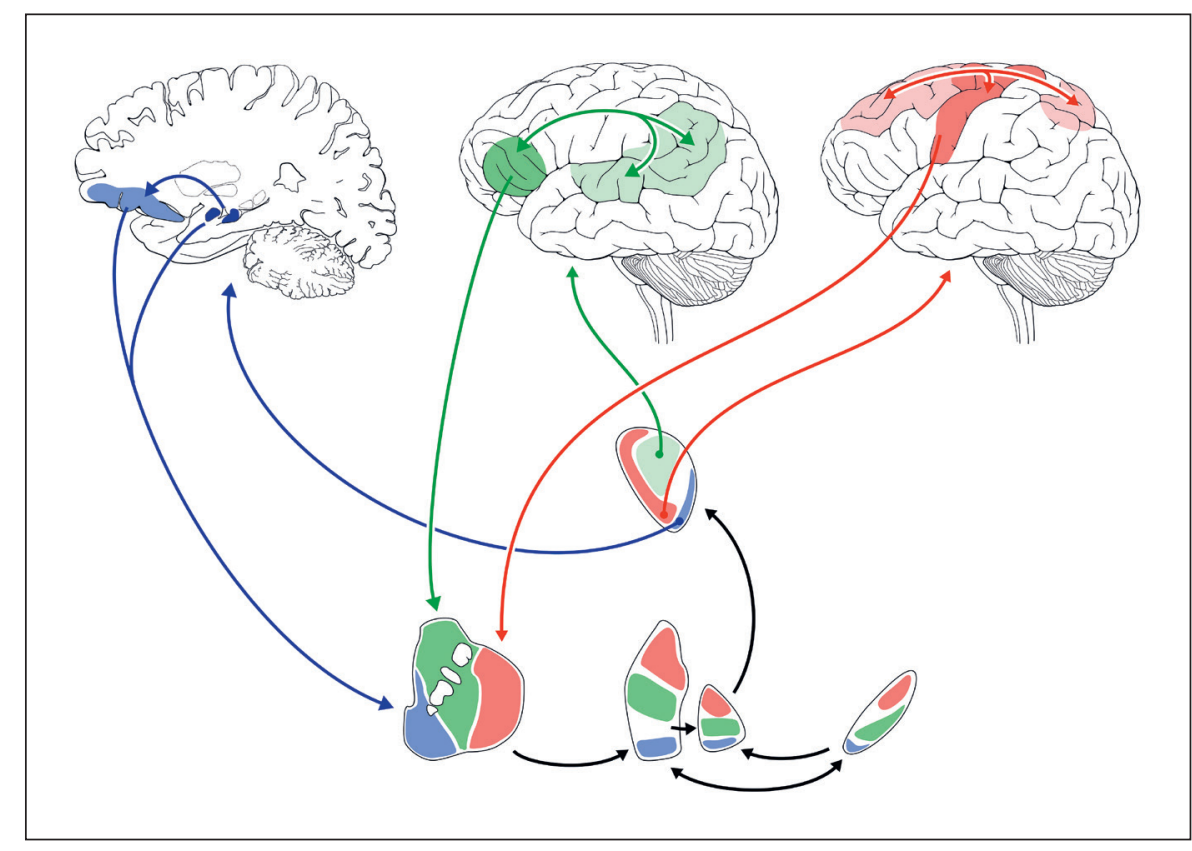

there are common pathways connecting the striatum (bottom left), the external and internal globus pallidus, and the subthalamic nucleus (bottom right of Fig. 4). The basal ganglia project to the thalamus (middle of Fig. 4), which in turn has multiple efferents and afferents to the three brain systems.

These loops overlap with important sensorimotor connections of the cerebral cortex, representing an important, parallel organization of the brain. The loops are anatomically and functionally segregated, and relevant for specific domains of complex human communication [18-20]. The limbic loop includes, but is not limited to, the hippocampus and amygdala (dark blue, left panel of Fig. 4), which have efferents and afferents to the orbitofrontal cortex (light blue in Fig. 4). Also, the limbic loop includes the ventral striatum.

In psychiatry, among these systems, the best known is the language system. It has reciprocal connections and functions to map sound onto meaning, and to couple auditory input to verbal output. Language-specific regional activations largely overlap with the associative corticostriatal loop [21]. There are long-range corticocortical connections via the arcuate fascicle between its highly specialized sensory (Wernicke) and motor (Broca) components (middle panel of Fig. 4). Also, the frontal and temporal components of the language system have been shown to exert mutual inhibitory control [22], thus presenting the features of a balanced loop. fMRI studies sug- gest the existence of similar domain-specific long-range connections between specialized cortical regions and the limbic system, e.g., for emotional face processing, between the fusiform gyrus, the amygdala, and the orbitofrontal cortex $[23,24]$. In the motor domain, the capacity to recognize nonverbal information such as hand gestures is strongly linked to the performance of hand gestures [25], suggesting a parallel organization with direct connections between brain areas of action perception and those of action planning [26]. The cortical connections of the motor system include areas of executive control and action planning (rostral to primary motor cortex) and parietal areas of action perception (see right panel of Fig. 4). Thus, there are good reasons for assuming that these important sensorimotor systems are anatomically defined modules for the parallel processing of complex information in the associative, emotional, and executive domains.

\section{The Level of Cognition}

Schizophrenia is often characterized as a disorder of cognition. There is no unique definition of the term " $\operatorname{cog}$ nition." Here we refer to it as the integrated faculties of all specialized brain systems, including those referred to in the previous section. These integrated faculties cannot be mapped onto specific brain circuits. In fact, recent studies have suggested that the integration of cognitive functions at the highest level of brain organization may be mediated by fiber nodes or hubs; these convey convergent informa- 
tion from the subordinate sensorimotor systems and enteroceptive information from the body. These hubs were called "rich clubs," and they are defined as brain regions with more afferences than efferences [27].

Such hubs are the hippocampus, insula, precuneus, and anterior cingulate cortex, which are involved in manifold cognitive functions [27, 28]. They might be responsible for the integration, orchestration, and sequencing of human behavior and subjective experience into a unique stream of consciousness and consistent, goal-directed behavior. In fact, cognitive impairment in schizophrenia has mostly been associated with widespread brain-behavior correlations at the highest level of interaction between specialized brain systems. In contrast, the SyNoPsis project intends to match the clinical symptoms with the lower level of subordinate, functionally interpretable brain circuits in order to better understand the diverse clinical expressions of what for more than a century has been understood as "dissociation" in schizophrenia.

\section{The Behavioral Level}

Psychosis as a Fundamental Communication

Breakdown

For didactic purposes, "reality distortion" has often been invoked as the pivotal property of psychosis. Unfortunately, this traditional definition suggests that all nonpsychotic subjects would refer to a unique, socially accepted reality, which obviously is not the case. Humans live in countless diverse subjective realities, due to different information, beliefs, and spiritual, cultural, and social frames of reference. Nonetheless, they are able to communicate with others about their opinions and intentions. We must recognize that the deficit in psychosis is not the aberration from an absolute reality, but rather the incapacity to share experiences, intentions, and convictions with others. The consequence of this particular psychotic communication breakdown is social isolation or expulsion [29]. In fact, the rare cases of shared psychotic delusions ("folie à deux") are still worth publishing in case reports [30].

While "reality distortion" is an ambiguous and contextual concept, "psychotic communication breakdown" as outlined above can be broken down and operationally distinguished by its elements: the loss of a common frame of reference, the incapacity to realize this loss, ignorance or neglect of its negative consequences, and the drive to fight for solitary ideas, attitudes, or intentions, or, alternatively, to retreat from interpersonal contacts to avoid conflicts. Such a communication breakdown is not lim- ited to verbal arguments but can affect any major human communication domain including emotions and motor behavior. A description of this communication breakdown incorporates both the subjective experience of the patients and an objective evaluation which relies on the detailed observation of clinical signs.

\section{Major Domains of Human Communication}

Beyond the content of spoken language [31], detailed and human-specific information is exchanged not only by emotional expression via vegetative signs and complex instinctive behavior, but also by nonverbal motor communication, for instance, via gestures [32, 33], postures, and directed behavior [34]. This consideration is oriented towards a natural segregation of three important communication domains: language, emotions, and motor behavior. These domains interestingly resemble three basic psychic functions repeatedly identified by classic authors such as Hecker, Kraepelin, and Bleuler, who referred to them as "thinking, feeling, and will," which, according to Eugen Bleuler, would be "dissociated" in schizophrenia [35].

Considering these communication domains in terms of interpersonal information exchange, each of them can be considered in terms of expression and perception of complex behavioral patterns. Applied to the behavioral and subjective abnormalities in psychosis, unusual semantic or associative verbal expressions can unequivocally be assigned to the language domain, as well as abnormal perceptions of spoken language in the form of AVHs. Similarly, weird, unexpected, inadequate, ambiguous, or reduced motor expressions may seriously impair nonverbal communication, as does the incapacity to correctly interpret gestures or intentional movements of others, which has been found in patients with schizophrenia $[36,37]$. Finally, an abnormally excited or protracted emotional expression combined with a pervasive perception bias regarding the emotions of others as an existential threat or supernatural power can be attributed to the emotional domain $[38,39]$.

We recognize that the information exchange between humans goes far beyond the presently described specialized communication domains and includes many signals about the homeostatic or endocrine state of the organism, age, sex, strength or personal health, and care. Yet, these signals cannot be directly linked to the functions of specialized higher-order brain systems, and only generically to psychotic behavior. Thus, they are considered no further in this context. 
Translational Psychopathology: Matching Psychotic Symptoms with Brain Systems

\section{Methodology}

For the SyNoPsis project, current diagnostic assessment instruments and textbooks (including historical descriptions) were screened for diagnostic and clinically relevant features of schizophrenia and related psychoses in order to determine their suitability for assignation to the functions of the above-described sensorimotor brain systems by formal criteria. In addition to the most influential psychopathological schools, we also considered conceptually complementary nosologies of French (e.g., bouffée délirante), Scandinavian (e.g., brief reactive psychosis), and German (e.g., cycloid, affective, and catatonic disorders) authors. The respective theoretical frameworks were considered no further.

Only descriptions of psychotic behavior and personal experience that could be unequivocally matched with one of the identified communicative domains and the respective sensorimotor systems were further considered. The following examples illustrate this procedure.

\section{Attributions to the Language System}

Classic "thought disorders" were attributed to the executive function of the language system if they could be defined as an abnormal expression of speech, i.e., grammatical and logical errors, unconventional associations and vocabulary, and an abnormally increased or decreased speed or content [40-48]. AVHs, on the other hand, were attributed to the sensory functions of the language system, since they consist in an abnormal perception of speech $[9,49-51]$.

Attributions to the Limbic System

As outlined above, several classic core symptoms cannot be mapped unambiguously onto specific brain systems; rather they must be the result of complex cognitive processes involving more than one specific brain system and, therefore, common final pathways of different possible causes. An example of this type of symptom is "delusion," which is traditionally referred to as a disorder of the "content of thought" caused by an "error of judgement" $[52,53]$.

Delusions are communicated verbally, and their content may involve logical errors, thus indicating languagerelated dysfunctions. In many cases, however, the outstanding and most dysfunctional feature of delusions is their exceptional emotional valence related to an existentially afflicting content, which may be negative, such as the threat of poisoning, persecution, or condemnation, or positive with reference to supernatural powers or spiritual salvation. They are further characterized by their exceptional and dysfunctional urgency to communicate, impose, and perseverate, and to fight or avoid a threat, irrespective of all the negative consequences [54, 55]. Thus, an attribution to the emotional domain of communication is possible for the emotional valence of delusions but not for the error of judgement per se. This view is consistent with the RDoC's negative valence constructs for delusions, such as acute threat, potential threat, sustained threat, and frustrative nonreward [56], and empirical studies support the link of paranoid experience of threat and delusions of reference to abnormalities of the limbic system [57-60]. Furthermore, modern rating scales for delusions, such as the Psychotic Symptom Rating Scales (PSYRATS) [61] or the Delusions-SymptomsStates Inventory (DSSI) [62], focus on other aspects, particularly on the emotional content of delusions.

\section{Attributions to the Motor System}

Most perspicuous is the attribution of characteristic catatonic symptoms to the motor system [63]. This is true especially for hyperkinesia, hypokinesia, and parakinetic symptoms like grimacing or tic-like movement abnormalities, but also for bizarre gestures and postures. Furthermore, other motor phenomena such as parkinsonism or higher executive functions including action planning, nonverbal decisions to act, and volition were attributed to the extended motor system [64].

\section{The Instrument: The Bern Psychopathology Scale}

(BPS) for the Assessment of System-Specific Psychotic

\section{Symptoms}

The BPS was developed based on the described methodology and provides a systematic and operational catalog of individual psychotic behavior and subjective experience that can be uniquely matched with one of the candidate sensorimotor brain systems referred to in the SyNoPsis project. This implies that the BPS is neither a comprehensive historical inventory of schizophrenia symptoms nor a checklist of current diagnostic criteria for schizophrenia, since it excludes all terms that are ambiguous or unclear regarding their relationship to our current knowledge about the functional anatomy of the brain. It must therefore be understood as a tool permitting mechanistic brain-behavior relationships in psychotic disorders but not explaining or describing every facet of schizophrenia. 
The Structure of the Scale

The BPS allows the assessment of psychotic symptoms separately for the three behavioral domains of language, affectivity, and motor dimension in terms of a "negative" or "positive" deviation from normal, resulting in six clinical syndromes (negative and positive for each of the three dimensions). Every single negative and positive symptom is matched with one explicitly defined physiological function of the respective system ${ }^{4}$. Each rating of the BPS refers to a defined period, which can vary from a snapshot to a long observation period. This allows monitoring symptom changes with repeated measurements.

The assessment is dimensional, i.e., the global symptom severity of each domain can be scaled at different levels of severity. Good internal consistency and external validity of the BPS have been shown in several studies [59, 65-74].

In the following chapter, we will summarize recent translational studies which support the system-specific aggregation of psychotic symptoms and are consistent with the SyNoPsis framework.

\section{Mapping Symptoms onto Brain Systems: Empirical Evidence for SyNoPsis}

The following selective review gives an overview of empirical translational studies supporting the relationship between clinical symptoms and the proposed candidate brain systems.

\section{Language: The Semantic Domain}

Formal Thought Disorders

Language is the main communication channel for the assessment of psychiatric disorders. Psychopathological tradition refers irregularities of the form and content of spoken language to the inchoate entity of "thought." The term formal thought disorder (FTD) refers to a heterogeneous group of dysfunctions concerning speech production and perception [43], possibly with a distinct underlying pathophysiology. In the context of the SyNoPsis project, spoken language is treated as an expression of the brain's language system including its associative regions. In particular, FTDs are understood as quantitative (speed, amount) and qualitative (syntactic, grammatical, associative, semantic) aberrations from linguistic conventions during speech. This operational definition has been sys-

\footnotetext{
4 E.g., normal, reduced ("negative"), or increased ("positive") speech time, speed, or content.
}

tematically realized in the BPS. It is also consistently reflected in other modern instruments for assessing FTDs, including the Scale for the Assessment of Thought, Language and Communication (TLC) [75], the Thought and Language Index (TLI) [76], or the rating scale for the assessment of objective and subjective formal Thought and Language Disorder (TALD) [77]. However, only the BPS and the TALD include different dimensions of FTDs.

Early electrophysiological studies have indicated a specific role of the language system in subgroups of schizophrenia, based on the results of left hemispheric reductions of the auditory $\mathrm{P} 300$ related to performance in verbal, but not visuospatial, memory tasks [78]. An fMRI study indicated activation abnormalities of the left temporal regions related to FTDs [40]. Horn et al. [41] showed a highly significant correlation between the severity of FTDs and cerebral alterations in the language system, e.g., a reduced left temporal gray matter volume in Wernicke's region, and local hyperperfusion in the same area and in the inferior frontal lobe in Broca's region. The perfusion values of the most disturbed patients were at the level of those found in patients with neurological disorders such as epilepsy or migraine. Recently, behavioral alterations in the BPS language dimension were linked to changes in cerebral blood flow (CBF) within the cerebral language system, i.e., right Heschl's gyrus [60]. Furthermore, a linear brain-behavior association with white matter (WM) microstructure was detected with the BPS language score ranging from inhibition (negative FTDs) to normal speech (no FTDs) and disinhibition (positive FTDs). In particular, patients with behavioral inhibition of language had the highest fractional anisotropy values, suggesting that a structural specialization of language tracts with increased WM directionality (fractional anisotropy values) may increase vulnerability to negative FTDs. In contrast, a lower WM directionality in language tracts increases vulnerability to positive FTDs [72]. Further studies have supported the particular link of FTDs to structural [79-81] and functional [41, 82-84] disorders of the language system.

In summary, there is growing evidence that FTDs in schizophrenia involve a disturbance of basic language functions and brain areas of the language system, consistent with the findings of other groups $[42,44-46,85,86]$.

\section{Auditory Verbal Hallucinations}

Hallucinations are frequent in schizophrenia. Although they are an exclusively subjective phenomenon, they can be taken as they are, i.e., as reports about perceptions that cannot be verified by others. The formal criteria 
for attributing a hallucination to one of the candidate systems are its sensory modality, complexity, and direct or indirect indications of its emotional valence. Reports about hallucinations in any sensory modality can have unequivocal, positive (e.g., divine appearance), or negative (e.g., devil's odor) emotional valence, which is attributed to the emotional domain on the BPS. AVHs, however, can be specifically and directly attributed to the language system, since the misperception contains spoken language.

In the past two decades, several studies have been published on AVH, elucidating the involved brain regions, introducing novel, symptom-specific physical treatment, and providing proofs of concept regarding the causal relationship between the described activation patterns of components of the auditory and language system and the reported severity of an AVH. Most of these studies found alterations in acoustic and language areas in subjects with current AVHs [87]. The topic is of particular interest, since it demonstrates that empirical study of exclusively subjective psychic phenomena is possible. An early fMRI study showed that in patients with schizophrenia, AVHs were associated with activation of the primary auditory cortex (Heschl's gyrus) along with the inferior frontal lobe (Broca's region) of the language-dominant hemisphere. In one patient who reported a strong negative emotional valence of the hallucinated voice, an additional activation of the amygdala was found [9]. A later diffusion tensor imaging study suggested an increased connectivity within the left arcuate fascicle, which is a major intrahemispheric fiber tract connecting frontal to temporal components of the language system. This finding was specific for schizophrenia patients with frequent hallucinations compared to schizophrenia patients who had never hallucinated as well as healthy controls [49]. Furthermore, it was demonstrated that the effect of phasic activation of Heschl's gyrus during hallucinations could not be explained by external stimulation, but rather by sequestration of temporal lobe resources by internal processes [88]. Finally, behavioral alterations in the BPS language dimension, particularly including AVHs, were associated with increased CBF in the right Heschl gyrus [89].

Thus, there is increasing evidence from our and other groups that hallucinations in schizophrenia involve a disturbance of brain areas of the language system, among other brain regions [90].

\section{Affectivity: The Limbic Domain}

Reports of persons affected by psychotic disorders often refer to experiences of existential threat or of super- natural power. In Jasper's phenomenology, which is still implicitly present in current symptom definitions, they are explained as secondary to a primary cognitive disorder, i.e., an incomprehensible error of judgement [5]. However, delusions of poisoning, persecution, or damnation - or, conversely, a divine mandate or universal revelations - are existential experiences with extraordinary affective valence. Yet, these typical psychotic contents can hardly be identified as a simple expression of a mood disorder. In fact, the emotional valence is sometimes denied in psychosis, presenting a psychological paradox: an existential threat such as the conviction of being poisoned does not always provoke a subjective perception of anxiety, and the conviction of possessing supernatural powers is accompanied by apparently unmotivated suspiciousness and aggressive actions directed against purported enemies or injustice. Some of our patients have explained this paradox with a subjective switch into a "combat mode." This psychological state thus can be formally distinguished from the typical, consistent changes in selfesteem, activity, and mood observed in affective disorders.

\section{Power and Threat: The Paranoid Syndrome}

What, then, is the characteristic feature of emotional dysregulation in psychosis? The content and behavior associated with the classic paranoid syndrome indicates a pivotal role of the atavistic sensation of danger [91]. The related ominous feeling is accompanied by an imperative urgency to identify the origin of the threat, and to avoid or destroy it. Such an emotional state can be related to the functions of the limbic system, with its structures involved in sensations of undetermined threat (bed nucleus of the stria terminalis) [92], incentive salience (ventral striatum) $[93,94]$, and approach avoidance (amygdalaventral striatum) [95]. At the behavioral level, they can be coherently linked to paranoid delusions, avoidant behavior, aggression, or general suspiciousness.

The most evident denominator of the paranoid syndrome is an existential threat, which is sometimes, but not always, accompanied by subjective anxiety. This is often linked to avoidance in terms of social retreat, or to aggressive behavior, and can be understood as "fight-orflight" reactions to the threat. In such a psychological context, violent behavior would then be a defense against a perceived threat, often to fight a delusional injustice [96]. In a formal examination, the latter case is particularly astonishing, since the delusional adversary often has an overwhelming supremacy, such as the state, the police, the mafia, or the devil. This implies that the person feels 
powerful enough to fight this enemy. In some typical clinical situations, this is very evident, and the phenomenon is called "grandiosity," or the delusion of having supernatural powers.

With regard to indications for the paranoid syndrome to be linked to the limbic system, the BPS includes the axis of psychotic anxiety and elation. It is objectively expressed in vegetative signs, and subjectively in tension or relaxation. Indirect signs of limbic dysfunction are delusions of abnormal threats or powers. Consistently, we have demonstrated that gray matter abnormalities in a key region of the limbic system, i.e., the ventral striatum, were specifically related to emotional dysregulation in schizophrenia, but at the same time unrelated to schizophrenia in general [59]. Furthermore, the probability of a structural connection between the ventral striatum and the amygdala was increased as a function of paranoid symptoms [97]. Moreover, behavioral alterations in the BPS affectivity dimension - such as delusions of threat, suspiciousness, or unpleasant body sensations - were linked with an increased resting-state CBF in the left amygdala [60], and thus provide evidence for the hypothesized association between limbic dysfunction and clinical presentations of paranoid threat and persecutory delusions [94, 98]. At the behavioral level, interpersonal space regulation was linked to BPS affectivity ratings: patients with current paranoid threat spontaneously kept more than twice the interpersonal distance to a stranger than did patients without paranoid threat or even healthy controls. In contrast, patients experiencing grandiosity approached strangers much more closely than any other group [73]. Thus, the distinction between paranoid threat and grandiosity is reflected in the approach avoidance behavior of patients, as well as in specific alterations to the limbic system. Increased interpersonal distance had 93\% sensitivity and $83 \%$ specificity for identifying paranoid threat among schizophrenia patients [73].

Our reports are in line with and extend previous studies showing an association between single symptoms, such as paranoia [57], delusions [99], threat [100], or reality distortion [101], and alterations in the limbic and, particularly, the salience system.

\section{Motor Behavior: The Executive Domain}

Motor Symptoms and Schizophrenia

Movement disorders are part of the traditional symptom spectrum of schizophrenia, in particular of the catatonic subtype [64, 102, 103]. However, movement disorders have also been ambiguous since the advent of antipsychotic medications and their extrapyramidal side effects. Furthermore, mild deficits in motor skills have been interpreted as signs of neurodevelopmental delay and were described as "neurological soft signs."

In order to stimulate research on schizophrenia motor symptoms, we proposed to redefine the symptoms based on their formal features: an increase or decrease in movement, abnormal sequencing, and the duration of interruptions. Such parameters have been successfully linked to brain structures and functions and to clinical features $[63,64]$. The approach is consistent with the intention of the DSM-5 to relaunch research on catatonia, disengaging it from schizophrenia [104].

Motor abnormalities are increasingly being recognized as markers for the risk of psychosis or course of schizophrenia $[105,106]$, as they occur in healthy firstdegree relatives of patients with schizophrenia [107] and in subjects at a clinically high risk of developing psychoses $[108,109]$. They predict poor cognitive outcomes in first-episode patients [110].

\section{Quantitative Movements and Movement Patterns}

Assessment of motor abnormalities is usually qualitative, and based on expert ratings. However, this has been challenged by objective measurements [111]. Actigraphy has demonstrated that continuous assessment of movement allows the extraction of meaningful parameters such as the average diurnal and nocturnal motor activity, the duration of immobility, or the statistical predictability of movement patterns and their relation to clinical features [111-116]. Notably, a measurable disorganization of movement patterns was related to disorganization of complex behavior and positive symptoms in schizophrenia [114]. Actigraphy may also monitor the course of negative symptoms, even across episodes [116, 117].

In the context of the SyNoPsis project, the results are important, since they allow the required translation from empirical measures of psychotic behavior to brain structures and functions. In fact, in several studies the motor abnormalities related to schizophrenia or its subtypes have been found to map onto the cerebral motor circuit $[63,74,118-120]$. In particular, the observed hypokinesia, i.e., reduction of motor activity, is associated with an aberrant coupling of cortical and subcortical motor areas. This association has been corroborated by data on gray matter density, gray matter perfusion, and WM properties $[63,121]$.

Catatonia

Catatonia is a classic syndrome of schizophrenia. Its importance for diagnosis and research, however, has 
decreased over time. It refers to disturbances of simple movements, complex movement patterns, action planning, and volition, as well as vegetative abnormalities [64, 122]. These aberrations were described as quantitative in terms of hyperactivity and hypoactivity, but only the latter has become the tacit synonym for catatonia in its entirety in recent years. Qualitative abnormalities such as flexibilitas cerea, parakinetic phenomena, ambivalence, ambitendency, or negativism are also included in the classic syndrome.

Several reasons have been invoked to explain the fading of these complex behavioral disorders from clinical and scientific awareness [64]. While their presence in clinical reality is not essentially questioned, their differential diagnosis has become increasingly fuzzy. Catatonia can be life-threatening, but the extensive clinical literature lacks operational consistency for diagnosis and treatment. This gap between research, clinical handling, and the importance of related conditions contributed to the decision to separate catatonia from schizophrenia, and to treat it as a distinct symptom for research and clinical diagnosis in the DSM-5 [104, 123]. As an independent specifier, it can now be applied to different disorders. There are good reasons for assuming that the new positioning of catatonia in the DSM-5 will encourage research to better understand its clinical features and underlying brain physiology [122].

This prospect is supported by studies showing that, coinciding with the assumptions of the SyNoPsis project, there is a link of catatonia symptoms with alterations in the cerebral motor system [63]. In particular, we demonstrated resting-state hyperperfusion in the supplementary motor area (SMA) of subjects with current catatonia in schizophrenia [124]. This finding was specific to subjects suffering from current catatonia in the context of schizophrenia. In fact, the SMA perfusion was greatest in those with the retarded subtype of catatonia, characterized by prominent motor inhibition. Thus, this extreme form of motor inhibition is in line with a dysregulation of the motor system as described above. Other signs of catatonia, such as negativism or stereotypies, probably result from different dysfunctions of cortical motor areas.

\section{Nonverbal Communication: Gesture Production}

and Perception

One step from simple movements to clinical symptoms consists in investigation into the communicative value of motor expression, and the perception of its meaning. Intentional and involuntary complex movements carrying information about individual intentions, expec-

SyNoPsis: Mapping Schizophrenia

Symptoms onto Brain Systems tations, and judgements are crucial for successful human communication [125]. An ambiguous or contradictory expression or perception of gestures and postures may impair mutual comprehension and provoke severe conflicts.

Patients with schizophrenia frequently suffer from impaired hand gesture performance $[126,127]$ and they tend to use gestures less frequently [128]. Two studies noted an association of impaired gesture performance with frontal lobe dysfunction and motor abnormalities in schizophrenia $[25,126]$. In addition, patients have problems interpreting the hand gestures of others correctly [129]. Furthermore, they tend to misperceive neutral gestures as threatening [37] and incidental movements as gestures [36]. We demonstrated a generalized deficit such as in gesture performance, gesture knowledge, nonverbal perception, and tool use - in schizophrenia [25]. In contrast to controls, performance was correlated between the tasks assessing nonverbal social perception, gesture performance, gesture recognition, and tool use. The results indicated a consistent sensorimotor deficit pattern which was not explained by supramodal cognitive deficits such as in working memory [25]. The clinical importance of gesture performance deficits in schizophrenia was substantiated by the finding that gesture impairments predict poor functional outcome after 6 months [130].

\section{Clinical Implications of SyNoPsis}

We have been applying the perspective of SyNoPsis not only to research but also to clinical work for several years. The initial scope of developing a consequently naturalistic approach to schizophrenia research has been gradually extended to improve patient care. In the following, we report some examples of translations of our empirical results to treatment. Some are supported by empirical studies, others by clinical observations. They are consistent with the pathophysiological hypotheses, and support the clinical benefit derived from the novel semiotics for de-escalation strategies and therapeutic alliances.

\section{Translation of Brain Imaging Studies to Treatment}

The language system is involved in AVHs, and pathological coactivation of Heschl's gyrus is supposed to contribute to the physical quality of a real perception $[9,10]$. Inhibitory repetitive transcranial magnetic stimulation (rTMS) of the left temporal lobe was found to reduce the 
intensity of AVH [131]. Two recent studies by our group provided a proof of concept for the role of the language system in AVH, and indicated that Heschl's gyrus hyperactivity was the most reliable indicator of both symptom severity [132] and prediction of response to rTMS treatment [133]. Furthermore, the pathophysiological hypothesis developed from our studies has stimulated a neurobiologically well-documented case study of successful transcranial direct current stimulation in $\mathrm{AVH}$ [134].

Regarding the motor domain, several studies have supported the contribution of components of the extended motor system to disorganized, reduced, or defective intentional and communicative movements. In particular, a recent study on akinetic catatonia offered a direct hint on a clinical application. Regional SMA hyperactivity was found to be a possible cause of the severe behavioral inhibition, indicating that this cortical regional is a possible target for inhibitory rTMS [124].

We repeatedly made neurobiological findings in the limbic system specifically linked to the particular affective state of some paranoid syndromes, i.e., the overwhelming awareness of an existential threat or of supernatural powers. In particular, reduced gray matter of the ventral striatum and hyperactivity of the amygdala were found. Based on these findings, we hypothesize that in this clearly defined subgroup, the pathophysiology involves deep brain structures that are not in reach of rTMS or transcranial direct current stimulation. In theory, deep brain stimulation would be the proper method for reaching these deep-seated targets [135], and our studies indicate the specific patient population for this method. However, we have little hope that this could ever become standard treatment for this patient group, which, by definition, is pathologically suspicious and often lacks a feeling of illness and confidence in any medical treatment. On the other hand, there is an interesting convergence of our empirical results with findings from studies on hippocampal GABAergic mechanisms at the basis of dopaminergic effects in the ventral striatum [136]. A clinical stratification of patient groups according to the SyNoPsis domains might help to aim targeted drug research at those patients with clinical signs of limbic dysfunctions.

\section{The Clinical Benefits of a Neurobiologically Informed Psychopathology}

The dimensional psychopathology proposed by us identifies three behavioral domains and allows focusing on individual deficits of different patients as distinct, clinically identifiable, communicable, and teachable patterns.
In everyday clinical work, a distinction between these different patterns of communication deficits can be extraordinarily useful. In fact, the most captivating features of a psychotic disorder are driven by the communication domain which is most deeply disturbed: a severely thought-disordered patient will invite the interlocutor to argue; aggressive suspiciousness or defensive avoidance will elicit emotional reactions like warnings or compassionate gestures; and catatonic negativism or hyperactivity motivates caregivers to urge the patient to move or to stop acting. We have observed that these intuitive, common-sense reactions can lead to unnecessary escalations. Instead, a recognition and distinction of different patterns of dissociated behavior allows shifting the attention from the disordered to the intact communication domains, and using the latter for de-escalation and therapeutic alliance. In other words, communication with a psychotic patient should give leeway to the most disordered, nonreactive, or overly excitable domain and focus on communication based on the intact domains: a negativistic patient should not be urged, but intermittently invited with positive emotional signals; a paranoid patient should not be warned, but, with respectful distance, convinced by logical arguments; and a formally thought-disordered patient often becomes cooperative if verbal arguments are taken joyfully, and emotional signals demonstrate careful attention.

Similarly, the proposed distinction can help in focusing and reducing medication. In our experience, sedation and mood stabilizers are usually well accepted by and helpful for patients with affective tension, but not if the leading symptoms are in the language or in the motor domain. High-potency antipsychotics, on the other hand, are often refused by paranoid patients, since they subjectively reduce their intact cognitive capacities; however, they are helpful for catatonic and thought-disordered patients, without reducing their emotional capacities.

These observations have not yet been confirmed in controlled studies. However, they may help in providing orientation for clinical decisions in the absence of empirical evidence, and in formulating novel hypotheses for clinical research. In the meantime, one interesting clinical study by our group provided evidence for an important clinical sign to identify the perception of paranoid threat in psychotic patients, which often is clinically masked by a negative symptomatology in terms of avoidance. In fact, the BPS global affect rating was suitable to identify paranoid threat and psychotic elation, and to link them to the individual personal space, i.e., the distance perceived as comfortable between a subject and another person. 
Among a group of psychotic patients, only the subgroup characterized by the experience of paranoid threat had significantly increased their personal space as compared to controls ( $2.41 \mathrm{vs.} 1.11 \mathrm{~m})$. Its excellent sensitivity and specificity indicates that individual personal space assessment is a simple bedside test for the important subgroup of emotionally dysregulated paranoid patients [73]. This finding should be explicitly considered for inclusion in the education of caregivers and professionals, and for planning of psychiatric wards and housing.

\section{Summary and Outlook}

SyNoPsis introduced three neurobiologically informed behavioral dimensions: language, affectivity, and motor behavior. It developed and validated a clinical rating instrument, the BPS, which selects and disentangles psychotic symptoms according to their formal relationship to well-known higher-order brain systems specialized for human communication and intentional behavior. The original claim of a link of specific symptoms to candidate brain systems was supported by several empirical studies. Furthermore, clinical studies and observations have indicated that the novel semiotics proposed by SyNoPsis can help develop individually focused strategies to improve treatment and therapeutic alliance in order to prevent behavioral escalations and unnecessary side effects. Last but not least, SyNoPsis provides a valuable framework for didactic purposes.

Psychotic disorders are a severe burden, but also a fascinating expression of a possible disturbance of the highest functions of the human brain. Grasping their structural and dynamic patterns can help us better understand the natural basis of the human mind and behavior. The SyNoPsis project presented in this paper proposes a convergent, naturalistic approach linking behavior to known brain systems, and provides evidence for a natural, threedimensional structure of psychotic symptoms. However, from future studies we expect to gain important further insights into the within-systems dynamics, elucidating the role of their excitatory and inhibitory components and of the differential contributions of their hierarchical levels to specific behavioral and subjective phenomena.

\section{References}

1 Peralta V, Cuesta MJ: The nosology of psychotic disorders: a comparison among competing classification systems. Schizophr Bull 2003;29:413-425.

2 Insel T, Cuthbert B, Garvey M, Heinssen R, Pine DS, Quinn K, Sanislow C, Wang P: Research domain criteria (RDoC): toward a new classification framework for research on mental disorders. Am J Psychiatry 2010;167: 748-751.

3 Cuthbert BN: The RDoC framework: facilitating transition from ICD/DSM to dimensional approaches that integrate neuroscience and psychopathology. World Psychiatry 2014; 13:28-35

4 Carpenter WT Jr: The RDoC controversy: alternate paradigm or dominant paradigm? The Am J Psychiatry 2016;173:562-563.

5 Jaspers K: Allgemeine Psychopathologie. Ein Leitfaden für Studierende, Ärzte und Psychologen. Berlin, Springer, 1913

6 Inagaki TK, Eisenberger NI: Neural correlates of giving support to a loved one. Psychosom Med 2012;74:3-7.

7 Harris S, Kaplan JT, Curiel A, Bookheimer SY, Iacoboni M, Cohen MS: The neural correlates of religious and nonreligious belief. PLoS One 2009;4:e0007272.
8 Bastin C, Harrison BJ, Davey CG, Moll J, Whittle S: Feelings of shame, embarrassment and guilt and their neural correlates: a systematic review. Neurosci Biobehav Rev 2016;71: 455-471.

9 Dierks T, Linden DEJ, Jandl M, Formisano E, Goebel R, Lanfermann H, Singer W: Activation of Heschl's gyrus during auditory hallucinations. Neuron 1999;22:615-621.

10 Wernicke C: Grundriss der Psychiatrie in klinischen Vorlesungen. Leipzig, Verlag von Georg Thieme, 1900, vol 1, p 201.

11 Skinner BF: Science and Human Behavior. Michigan, Macmillan, 1953.

12 Hempel CG: Fundamentals of taxonomy; in Hempel CG (ed): Aspects of Scientific Explanation. New York, Free Press, 1965, pp 137154.

13 Aragona M: Neopositivism and the DSM psychiatric classification. An epistemological history. Part 1: theoretical comparison. Hist Psychiatry 2013;24:166-179.

14 Ryle G: The Concept of Mind. Taylor \& Francis e-Library, 2009.

15 Singh SS, Khundrakpam B, Reid AT, Lewis JD, Evans AC, Ishrat R, Sharma BI, Singh RK: Scaling in topological properties of brain networks. Sci Rep 2016;6:24926.
16 Obeso JA, Rodriguez-Oroz MC, Stamelou M, Bhatia KP, Burn DJ: The expanding universe of disorders of the basal ganglia. Lancet 2014; 384:523-531.

17 Catani M, de Schotten MT: Atlas of Human Brain Connections. Oxford, Oxford University Press, 2015.

18 Jahanshahi M, Obeso I, Rothwell JC, Obeso JA: A fronto-striato-subthalamic-pallidal network for goal-directed and habitual inhibition. Nat Rev Neurosci 2015;16:719-732.

19 Alexander GE, DeLong MR, Strick PL: Parallel organization of functionally segregated circuits linking basal ganglia and cortex. Annu Rev Neurosci 1986;9:357-381.

20 Pauli WM, O'Reilly RC, Yarkoni T, Wager TD: Regional specialization within the human striatum for diverse psychological functions. Proc Natl Acad Sci USA 2016;113: 1907-1912.

21 Chan SH, Ryan L, Bever TG: Role of the striatum in language: syntactic and conceptual sequencing. Brain Lang 2013;125:283-294.

22 Frith CD, Friston KJ, Herold S, Silbersweig D, Fletcher P, Cahill C, Dolan RJ, Frackowiak RS, Liddle PF: Regional brain activity in chronic schizophrenic patients during the performance of a verbal fluency task. Br J Psychiatry 1995; 167:343-349.
SyNoPsis: Mapping Schizophrenia Symptoms onto Brain Systems
Neuropsychobiology 2017;75:100-116 DOI: $10.1159 / 000485221$ 
23 Frick A, Howner K, Fischer H, Kristiansson M, Furmark T: Altered fusiform connectivity during processing of fearful faces in social anxiety disorder. Transl Psychiatry 2013; 3:e312.

24 Haxby JV, Hoffman EA, Gobbini MI: Human neural systems for face recognition and social communication. Biol Psychiatry 2002;51:5967.

25 Walther S, Stegmayer K, Sulzbacher J, Vanbellingen T, Müri R, Strik W, Bohlhalter S: Nonverbal social communication and gesture control in schizophrenia. Schizophr Bull 2015;41:338-345.

26 Lindenberg R, Uhlig M, Scherfeld D, Schlaug G, Seitz RJ: Communication with emblematic gestures: shared and distinct neural correlates of expression and reception. Hum Brain Mapp 2012;33:812-823.

27 van den Heuvel MP, Sporns O, Collin G, Scheewe T, Mandl RCW, Cahn W, Goñi J, Hulshoff Pol HE, Kahn RS: Abnormal rich club organization and functional brain dynamics in schizophrenia. JAMA Psychiatry 2013;70:783-792.

28 Park H-J, Friston K: Structural and functional brain networks: from connections to cognition. Science 2013;342:1238411.

29 Bengtsson-Tops A, Hansson L: Quantitative and qualitative aspects of the social network in schizophrenic patients living in the community. Relationship to sociodemographic characteristics and clinical factors and subjective quality of life. Int J Soc Psychiatry 2001; 47:67-77.

30 Shah K, Breitinger S, Avari J, Francois D: Late-onset folie à deux in monozygotic twins. Schizophr Res 2017;182:142-143.

31 Dunbar RI, Marriott A, Duncan ND: Human conversational behavior. Hum Nat 1997;8: 231-246.

$32 \mathrm{McNeill} \mathrm{D}$ : So you think gestures are nonverbal? Psychol Rev 1985;92:350-371.

33 Walther S, Mittal VA: Why we should take a closer look at gestures. Schizophr Bull 2016; 42:259-261.

34 Hall JA, Knapp ML: Nonverbal Communication. Boston, De Gruyter, 2013.

35 Bleuler E: Dementia Praecox or the Group of Schizophrenias. New York, International Universities Press, 1911.

36 White TP, Borgan F, Ralley O, Shergill SS: You looking at me? Interpreting social cues in schizophrenia. Psychol Med 2016;46:149160.

37 Bucci S, Startup M, Wynn P, Baker A, Lewin TJ: Referential delusions of communication and interpretations of gestures. Psychiatry Res 2008;158:27-34.

38 Bach DR, Buxtorf K, Grandjean D, Strik WK: The influence of emotion clarity on emotional prosody identification in paranoid schizophrenia. Psychol Med 2009;39:927-938.

39 Bach DR, Herdener M, Grandjean D, Sander D, Seifritz E, Strik WK: Altered lateralisation of emotional prosody processing in schizophrenia. Schizophr Res 2009;110:180-187.
40 Kircher T, Liddle PF, Brammer MJ, Williams SC, Murray RM, McGuire PK: Neural correlates of formal thought disorder in schizophrenia: preliminary findings from a functional magnetic resonance imaging study. Arch Gen Psychiatry 2001;58:769-774.

41 Horn H, Federspiel A, Wirth M, Müller TJ, Wiest R, Wang J-J, Strik W: Structural and metabolic changes in language areas linked to formal thought disorder. Br J Psychiatry 2009; 194:130-138.

42 Liddle PF, Friston KJ, Frith CD, Hirsch SR, Jones T, Frackowiak RS: Patterns of cerebral blood flow in schizophrenia. Br J Psychiatry 1992:160:179-186.

43 DeLisi LE: Speech disorder in schizophrenia: review of the literature and exploration of its relation to the uniquely human capacity for language. Schizophr Bull 2001;27:481-496.

44 Sabri O, Erkwoh R, Schreckenberger M, Owega A, Sass H, Buell U: Correlation of positive symptoms exclusively to hyperperfusion or hypoperfusion of cerebral cortex in nevertreated schizophrenics. Lancet 1997;349: 1735-1739.

45 Lahti AC, Weiler MA, Holcomb HH, Tamminga CA, Carpenter WT, McMahon R: Correlations between $\mathrm{rCBF}$ and symptoms in two independent cohorts of drug-free patients with schizophrenia. Neuropsychopharmacology 2006;31:221-230.

46 Kaplan RD, Szechtman H, Franco S, Szechtman B, Nahmias C, Garnett ES, List S, Cleghorn JM: Three clinical syndromes of schizophrenia in untreated subjects: relation to brain glucose activity measured by positron emission tomography (PET). Schizophr Res 1993;11:47-54.

47 McGuire PK, Quested D, Spence S, Murray R, Frith C, Liddle P: Distinct neural correlates of "positive" and "negative" thought disorder. Schizophr Res 1998;2:111.

48 Hart M, Lewine RR: Rethinking thought disorder. Schizophr Bull 2017, Epub ahead of print.

49 Hubl D, Koenig T, Strik W, Federspiel A, Kreis R, Boesch C, Maier SE, Schroth G, Lovblad K, Dierks T: Pathways that make voices: white matter changes in auditory hallucinations. Arch Gen Psychiatry 2004;61: 658-668.

50 Strik W, Dierks T, Hubl D, Horn H: Hallucinations, thought disorders, and the language domain in schizophrenia. Clin EEG Neurosci 2008;39:91-94.

51 Waters F, Fernyhough C: Hallucinations: a systematic review of points of similarity and difference across diagnostic classes. Schizophr Bull 2017;43:32-43.

52 Freeman D: Suspicious minds: the psychology of persecutory delusions. Clin Psychol Rev 2007;27:425-457.

53 Feeney EJ, Groman SM, Taylor JR, Corlett PR: Explaining delusions: reducing uncertainty through basic and computational neuroscience. Schizophr Bull 2017;43:263-272.
54 Freeman D, Garety PA: Connecting neurosis and psychosis: the direct influence of emotion on delusions and hallucinations. Behav Res Ther 2003;41:923-947.

55 Garety PA, Gittins M, Jolley S, Bebbington P, Dunn G, Kuipers E, Fowler D, Freeman D Differences in cognitive and emotional processes between persecutory and grandiose delusions. Schizophr Bull 2013;39:629-639.

56 MacDonald AW 3rd: Studying delusions within Research Domain Criteria: the challenge of configural traits when building a mechanistic foundation for abnormal beliefs. Schizophr Bull 2017;43:260-262.

57 Pinkham AE, Liu P, Lu H, Kriegsman M, Simpson C, Tamminga C: Amygdala hyperactivity at rest in paranoid individuals with schizophrenia. Am J Psychiatry 2015;172:784-792.

58 Tao H, Wong GH, Zhang H, Zhou Y, Xue Z, Shan B, Chen EY, Liu Z: Grey matter morphological anomalies in the caudate head in firstepisode psychosis patients with delusions of reference. Psychiatry Res 2015;233:57-63.

59 Stegmayer K, Horn H, Federspiel A, Razavi N, Bracht T, Laimböck K, Strik W, Dierks T, Wiest R, Müller TJ, Walther S: Ventral striatum gray matter density reduction in patients with schizophrenia and psychotic emotional dysregulation. Neuroimage Clin 2014;4:232-239.

60 Strik W, Stegmayer K, Federspiel A, Wiest R, Walther S: Cerebral blood flow reveals relationships of three schizophrenia symptom dimensions with amygdala, Heschl's gyrus, and anterior cingulate cortex. Schizophr Bull 2015;41:S239.

61 Haddock G, McCarron J, Tarrier N, Faragher EB: Scales to measure dimensions of hallucinations and delusions: the Psychotic Symptom Rating Scales (PSYRATS). Psychol Med 1999;29:879-889.

62 Bedford A, Deary IJ: The Delusions-Symptoms-States Inventory (DSSI): construction, applications and structural analyses. Pers Individ Dif 1999;26:397-424.

63 Walther S: Psychomotor symptoms of schizophrenia map on the cerebral motor circuit. Psychiatry Res 2015;233:293-298.

64 Walther S, Strik W: Motor symptoms and schizophrenia. Neuropsychobiology 2012;66: 77-92.

65 Strik W, Wopfner A, Horn H, Koschorke P, Razavi N, Walther S, Wirtz G: The Bern Psychopathology Scale for the assessment of system-specific psychotic symptoms. Neuropsychobiology 2010;61:197-209.

66 Lang FU, Stierlin AS, Stegmayer K, Walther S, Becker T, Jäger M: Factor structure of the Bern Psychopathology Scale in a sample of patients with schizophrenia spectrum disorders. Eur Psychiatry 2015;30:880-884.

67 Bracht T, Heidemeyer K, Koschorke P, Horn H, Razavi N, Wopfner A, Strik W, Walther S: Comparison of objectively measured motor behavior with ratings of the motor behavior domain of the Bern Psychopathology Scale (BPS) in schizophrenia. Psychiatry Res 2012; 198:224-229. 
68 Lang FU, Müller-Stierlin AS, Walther S, Stegmayer K, Becker T, Jäger M: Dimensional approaches to schizophrenia: a comparison of the Bern Psychopathology scale and the fivefactor model of the Positive and Negative Syndrome Scale. Psychiatry Res 2016;239:284290.

69 Lang FU, Stegmayer K, Becker T, Jäger M: Schizophrenic psychoses with affect-dominant symptoms: contribution to a systemspecific approach (in German). Nervenarzt 2016;87:770-779.

70 Lang FU, Walther S, Stegmayer K, AndersonSchmidt H, Schulze TG, Becker T, Jäger M: Subtyping schizophrenia: a comparison of positive/negative and system-specific approaches. Compr Psychiatry 2015;61:115121.

71 Steinau S, Stegmayer K, Lang FU, Jäger M, Strik W, Walther S: Comparison of psychopathological dimensions between major depressive disorder and schizophrenia spectrum disorders focusing on language, affectivity and motor behavior. Psychiatry Res 2017; 250:169-176.

72 Viher PV, Stegmayer K, Giezendanner S, Federspiel A, Bohlhalter S, Wiest R, Strik W, Walther S: White matter correlates of the disorganized speech dimension in schizophrenia. Eur Arch Psychiatry Clin Neurosci 2016 Epub ahead of print.

73 Schoretsanitis G, Kutynia A, Stegmayer K, Strik W, Walther S: Keep at bay! - Abnormal personal space regulation as marker of paranoia in schizophrenia. Eur Psychiatry 2016 31:1-7.

74 Stegmayer K, Horn H, Federspiel A, Razavi N, Bracht T, Laimböck K, Strik W, Dierks T, Wiest R, Müller TJ, Walther S: Supplementary motor area (SMA) volume is associated with psychotic aberrant motor behaviour of patients with schizophrenia. Psychiatry Res 2014;223:49-51.

75 Andreasen NC: The Scale for the Assessment of Negative Symptoms (SANS): conceptual and theoretical foundations. Br J Psychiatry Suppl 1989;7:49-58.

76 Liddle PF, Ngan ET, Caissie SL, Anderson CM, Bates AT, Quested DJ, White R, Weg R: Thought and Language Index: an instrument for assessing thought and language in schizophrenia. Br J Psychiatry 2002;181:326-330.

77 Kircher T, Krug A, Stratmann M, Ghazi S, Schales C, Frauenheim M, Turner L, Fährmann P, Hornig T, Katzev M, Grosvald M, Müller-Isberner R, Nagels A: A rating scale for the assessment of objective and subjective formal Thought and Language Disorder (TALD). Schizophr Res 2014;160:216221.

78 Heidrich A, Strik W: Auditory P300 topography and neuropsychological test performance: evidence for left hemispheric dysfunction in schizophrenia. Biol Psychiatry 1997;41:327-335.
79 Horn H, Federspiel A, Wirth M, Müller TJ, Wiest R, Walther S, Strik W: Gray matter volume differences specific to formal thought disorder in schizophrenia. Psychiatry Res 2010;182:183-186.

80 Palaniyappan L, Mahmood J, Balain V, Mougin O, Gowland PA, Liddle PF: Structural correlates of formal thought disorder in schizophrenia: an ultra-high field multivariate morphometry study. Schizophr Res 2015;168: 305-312.

81 Bopp MH, Zöllner R, Jansen A, Dietsche B, Krug A, Kircher TT: White matter integrity and symptom dimensions of schizophrenia: a diffusion tensor imaging study. Schizophr Res 2017;184:59-68.

82 Horn H, Jann K, Federspiel A, Walther S, Wiest R, Müller T, Strik W: Semantic network disconnection in formal thought disorder. Neuropsychobiology 2012;66:14-23.

83 Arcuri SM, Broome MR, Giampietro V, Amaro E Jr, Kircher TT, Williams SC, Andrew CM, Brammer M, Morris RG, McGuire PK: Faulty suppression of irrelevant material in patients with thought disorder linked to attenuated frontotemporal activation. Schizophr Res Treatment 2012;2012:176290.

84 Stegmayer K, Stettler M, Strik W, Federspiel A, Wiest R, Bohlhalter S, Walther S: Resting state perfusion in the language network is linked to formal thought disorder and poor functional outcome in schizophrenia. Acta Psychiatr Scand 2017;136:506-516.

85 McGuire PK, Quested DJ, Spence SA, Murray RM, Frith CD, Liddle PF: Pathophysiology of "positive" thought disorder in schizophrenia. Br J Psychiatry 1998;173:231-235.

86 Arcuri SM, Amaro E, Bromme MR, Vieira G Sato JR, Brammer MJ, Williams SSC, Sameshima K, Baccalá L, Morris RG, McGuire PK: Functional disconnectivity and formal thought disorder in schizophrenia: integrating clinical, neuropsychological, neuroimaging and functional connectivty [sic!] data. Schizophr Res 2010;117:232-233.

87 Kompus K, Westerhausen R, Hugdahl K: The "paradoxical" engagement of the primary auditory cortex in patients with auditory verbal hallucinations: a meta-analysis of functional neuroimaging studies. Neuropsychologia 2011;49:3361-3369.

88 Hubl D, Koenig T, Strik W, Garcia LM, Dierks T: Competition for neuronal resources: how hallucinations make themselves heard. Br J Psychiatry 2007;190:57-62.

89 Stegmayer K, Strik W, Federspiel A, Wiest R, Bohlhalter S, Walther S: Specific cerebral perfusion patterns in three schizophrenia symptom dimensions. Schizophr Res 2017, Epub ahead of print.

90 Upthegrove R, Broome MR, Caldwell K, Ives J, Oyebode F, Wood SJ: Understanding auditory verbal hallucinations: a systematic review of current evidence. Acta Psychiatr Scand 2016;133:352-367.
91 Garety PA, Freeman D: The past and future of delusions research: from the inexplicable to the treatable. Br J Psychiatry 2013;203: 327-333.

92 Lebow MA, Chen A: Overshadowed by the amygdala: the bed nucleus of the stria terminalis emerges as key to psychiatric disorders. Mol Psychiatry 2016;21:450-463.

93 Heinz A, Schlagenhauf F: Dopaminergic dysfunction in schizophrenia: salience attribution revisited. Schizophr Bull 2010;36: 472-485.

94 Kapur S: Psychosis as a state of aberrant salience: a framework linking biology, phenomenology, and pharmacology in schizophrenia. Am J Psychiatry 2003;160:13-23.

95 Ramirez F, Moscarello JM, LeDoux JE, Sears RM: Active avoidance requires a serial basal amygdala to nucleus accumbens shell circuit. J Neurosci 2015;35:3470-3477.

96 Darrell-Berry H, Berry K, Bucci S: The relationship between paranoia and aggression in psychosis: a systematic review. Schizophr Res 2016;172:169-176.

97 Bracht T, Horn H, Strik W, Federspiel A, Razavi N, Stegmayer K, Wiest R, Dierks T, Müller TJ, Walther S: White matter pathway organization of the reward system is related to positive and negative symptoms in schizophrenia. Schizophr Res 2014;153:136-142.

98 Winton-Brown TT, Fusar-Poli P, Ungless MA, Howes OD: Dopaminergic basis of salience dysregulation in psychosis. Trends Neurosci 2014;37:85-94.

99 Menon M, Schmitz TW, Anderson AK, Graff A, Korostil M, Mamo D, Gerretsen P, Addington J, Remington G, Kapur S: Exploring the neural correlates of delusions of reference. Biol Psychiatry 2011;70:11271133.

100 Wolf DH, Satterthwaite TD, Calkins ME, Ruparel K, Elliott MA, Hopson RD, Jackson CT, Prabhakaran K, Bilker WB, Hakonarson H, Gur RC, Gur RE: Functional neuroimaging abnormalities in youth with psychosis spectrum symptoms. JAMA Psychiatry 2015;72:456-465

101 Palaniyappan L, Mallikarjun P, Joseph V, White TP, Liddle PF: Reality distortion is related to the structure of the salience network in schizophrenia. Psychol Med 2011;41: 1701-1708.

102 Kendler KS: Phenomenology of schizophrenia and the representativeness of modern diagnostic criteria. JAMA Psychiatry 2016;73: 1082-1092.

103 Peralta V, Cuesta MJ: Motor abnormalities: from neurodevelopmental to neurodegenerative through "functional" (neuro)psychiatric disorders. Schizophr Bull 2017;43:956971.

104 Tandon R, Heckers S, Bustillo J, Barch DM, Gaebel W, Gur RE, Malaspina D, Owen MJ, Schultz S, Tsuang M, van Os J, Carpenter W: Catatonia in DSM-5. Schizophr Res 2013; 150:26-30. 
105 van Harten PN, Walther S, Kent JS, Sponheim SR, Mittal VA: The clinical and prognostic value of motor abnormalities in psychosis, and the importance of instrumental assessment. Neurosci Biobehav Rev 2017;80: 476-487.

106 Mittal VA, Bernard JA, Northoff G: What can different motor circuits tell us about psychosis? An RDoC perspective. Schizophr Bull 2017;43:949-955.

107 Koning JP, Tenback DE, van Os J, Aleman A, Kahn RS, van Harten PN: Dyskinesia and parkinsonism in antipsychotic-naive patients with schizophrenia, first-degree relatives and healthy controls: a meta-analysis. Schizophr Bull 2010;36:723-731.

108 Kindler J, Schultze-Lutter F, Michel C, Martz-Irngartinger A, Linder C, Schmidt SJ, Stegmayer K, Schimmelmann BG, Walther $S:$ Abnormal involuntary movements are linked to psychosis-risk in children and adolescents: results of a population-based study. Schizophr Res 2016;174:58-64.

109 Mittal VA, Walker EF: Movement abnormalities predict conversion to axis I psychosis among prodromal adolescents. J Abnorm Psychol 2007;116:796-803.

110 Cuesta MJ, Sánchez-Torres AM, de Jalón EG, Campos MS, Ibáñez B, Moreno-Izco L, Peralta V: Spontaneous parkinsonism is associated with cognitive impairment in antipsychotic-naive patients with first-episode psychosis: a 6-month follow-up study. Schizophr Bull 2014;40:1164-1173.

111 Walther S, Koschorke P, Horn H, Strik W: Objectively measured motor activity in schizophrenia challenges the validity of expert ratings. Psychiatry Res 2009;169:187190.

112 Walther S, Tschacher W, Strik W: The structure of movement patterns as predictor of schizophrenia symptom dimensions. Biol Psychiatry 2015;77:31S-32S.

113 Walther S, Stegmayer K, Horn H, Razavi N, Müller TJ, Strik W: Physical activity in schizophrenia is higher in the first episode than in subsequent ones. Front Psychiatry 2014;5:191.

114 Walther S, Ramseyer F, Horn H, Strik W, Tschacher W: Less structured movement patterns predict severity of positive syndrome, excitement, and disorganization. Schizophr Bull 2014;40:585-591.
115 Walther S, Horn H, Koschorke P, Müller TJ, Strik W: Increased motor activity in cycloid psychosis compared to schizophrenia. World J Biol Psychiatry 2009;10:746-751.

116 Walther S, Stegmayer K, Horn H, Rampa L, Razavi N, Müller TJ, Strik W: The longitudinal course of gross motor activity in schizophrenia - within and between episodes. Front Psychiatry 2015;6:10.

117 Murck H, Laughren T, Lamers F, Picard R, Walther S, Goff D, Sainati S: Taking personalized medicine seriously: biomarker approaches in phase IIb/III studies in major depression and schizophrenia. Innov Clin Neurosci 2015;12:26S-40S

118 Bracht T, Schnell S, Federspiel A, Razavi N, Horn H, Strik W, Wiest R, Dierks T, Müller TJ, Walther S: Altered cortico-basal ganglia motor pathways reflect reduced volitional motor activity in schizophrenia. Schizophr Res 2013;143:269-276.

119 Walther S, Federspiel A, Horn H, Razavi N, Wiest R, Dierks T, Strik W, Müller TJ: Resting state cerebral blood flow and objective motor activity reveal basal ganglia dysfunction in schizophrenia. Psychiatry Res 2011; 192:117-124.

120 Walther S, Federspiel A, Horn H, Razavi N, Wiest R, Dierks T, Strik W, Müller TJ: Alterations of white matter integrity related to motor activity in schizophrenia. Neurobiol Dis 2011;42:276-283.

121 Walther S, Stegmayer K, Federspiel A, Bohlhalter S, Wiest R, Viher PV: Aberrant hyperconnectivity in the motor system at rest is linked to motor abnormalities in schizophrenia spectrum disorders. Schizophr Bull 2017;43:982-992.

122 Walther S, Strik W: Catatonia. CNS Spectr 2016;21:341-348.

123 Heckers S, Tandon R, Bustillo J: Catatonia in the DSM - shall we move or not? Schizophr Bull 2010;36:205-207.

124 Walther S, Schäppi L, Federspiel A, Bohlhalter S, Wiest R, Strik W, Stegmayer K: Resting-state hyperperfusion of the supplementary motor area in catatonia. Schizophr Bull 2017;43:972-981.

125 Knapp M, Hall JA, Horgan TG: Nonverbal Communication in Human Interaction. Boston, Wadsworth, 2013.
126 Walther S, Vanbellingen T, Müri R, Strik W, Bohlhalter S: Impaired pantomime in schizophrenia: association with frontal lobe function. Cortex 2013;49:520-527.

127 Walther S, Vanbellingen T, Müri R, Strik W, Bohlhalter S: Impaired gesture performance in schizophrenia: particular vulnerability of meaningless pantomimes. Neuropsychologia 2013;51:2674-2678.

128 Lavelle M, Healey PG, McCabe R: Is nonverbal communication disrupted in interactions involving patients with schizophrenia? Schizophr Bull 2013;39:1150-1158.

129 Toomey R, Schuldberg D, Corrigan P, Green MF: Nonverbal social perception and symptomatology in schizophrenia. Schizophr Res 2002;53:83-91.

130 Walther S, Eisenhardt S, Bohlhalter S, Vanbellingen T, Müri R, Strik W, Stegmayer K: Gesture performance in schizophrenia predicts functional outcome after 6 months. Schizophr Bull 2016;42:1326-1333.

131 Hoffman RE, Boutros NN, Hu S, Berman RM, Krystal JH, Charney DS: Transcranial magnetic stimulation and auditory hallucinations in schizophrenia. Lancet 2000;355: 1073-1075.

132 Kindler J, Homan P, Jann K, Federspiel A, Flury R, Hauf M, Strik W, Dierks T, Hubl D: Reduced neuronal activity in language-related regions after transcranial magnetic stimulation therapy for auditory verbal hallucinations. Biol Psychiatry 2013;73:518-524.

133 Homan P, Kindler J, Hauf M, Hubl D, Dierks T: Cerebral blood flow identifies responders to transcranial magnetic stimulation in auditory verbal hallucinations. Transl Psychiatry 2012;2:e189.

134 Homan P, Kindler J, Federspiel A, Flury R, Hubl D, Hauf M, Dierks T: Muting the voice: a case of arterial spin labeling-monitored transcranial direct current stimulation treatment of auditory verbal hallucinations. Am J Psychiatry 2011;168:853-854.

135 Mikell CB, Sinha S, Sheth SA: Neurosurgery for schizophrenia: an update on pathophysiology and a novel therapeutic target. J Neurosurg 2016;124:917-928.

136 Heckers S, Konradi C: GABAergic mechanisms of hippocampal hyperactivity in schizophrenia. Schizophr Res 2015;167:411. 